This item was submitted to Loughborough's Research Repository by the author.

Items in Figshare are protected by copyright, with all rights reserved, unless otherwise indicated.

\title{
Groundwater exploration
}

PLEASE CITE THE PUBLISHED VERSION

PUBLISHER

(c) WEDC, Loughborough University

VERSION

VoR (Version of Record)

PUBLISHER STATEMENT

This work is made available according to the conditions of the Creative Commons Attribution-NonCommercialNoDerivatives 4.0 International (CC BY-NC-ND 4.0) licence. Full details of this licence are available at: https://creativecommons.org/licenses/by-nc-nd/4.0/

\section{LICENCE}

CC BY-NC-ND 4.0

\section{REPOSITORY RECORD}

Shankar, K. Ravi. 2019. “Groundwater Exploration”. figshare. https://hdl.handle.net/2134/28564. 
WATER IS THE basic need for any life to exist in this world. Prehistoric man was leading a nomadic life on the banks of rivers. With natural calamities such as floods, earthquakes etc. he was disturbed and up rooted from his dwelling place. With the advent of civilization the use of water increased by leaps and bounds, first for his drinking needs, then for supplementing agriculture, irrigation municipal requirements and later for industrial growth. Naturally, when surface water is in short supply one has to depend partly or wholly on ground water.

Groundwater is more desirable than surface water for at least six following reasons:-

- It is commonly free of pathogenic organisms and need no elaborate purification for domestic and industrial uses.

- Temperature is nearly constant which is a great advantage if the water is used for heat exchange.

- Turbidity and colour are generally negligible.

- Chemical composition is generally constant.

- Ground water storage is always greater than surface water storage, so that ground water supplies are not seriously affected by short duration droughts.

- Biological contamination in ground water is seldom noticed.

\section{Aim of investigation}

This paper is a result of a study done in the southern part of India.

The aim of the investigation was to assess the ground water potential in the unconfined aquifer, method of tapping ground water without any adverse effects, the rate and extent of salt water intrusion and then to suggest precautionary measures to prevent salt water intrusion. Electrical resistivity surveys were carried out in the field for locating the availability of water and its quality.

\section{Electrical resistivity method}

Resistivity, the inverse of electrical conductivity, is the resistance of the geologic medium to current flow when a potential difference is applied.

$\mathrm{R}=\mathrm{V} / \mathrm{I}$, where $\mathrm{R}$ is the resistance, $\mathrm{V}$ is the voltage and I is the current. For a given material being measured and inversely proportional to its cross-sectional area $\mathrm{R}=\vartheta \mathrm{L} /$ A or $\vartheta=\mathrm{RA} / \mathrm{L}$, where $\mathrm{P}$ is the characteristic resistivity of the geologic medium, $\mathrm{A}$ is the unit cross-sectional area and $\mathrm{L}$ is its length. Unit of resistivity are usually given in ohm - meters.
In the resistivity surveys, a direct current or low frequency alternating current is sent through the ground between the two metal electrodes. Because earth materials offer resistance to the passage of a current some voltage loss will occur as the current flows from one electrode to another. The voltage loss that occurs as the current moves through the ground is measured at other electrodes placed between the current electrodes.

Resistivity values are obtained by two different surface exploration methods. The first of these, called electrical sounding, involves vertical exploration. In this procedure, a series of stations are established and careful depth sounding are taken. These soundings are later transferred to a vertical cross-section. By evaluating the resistivity values, an understanding of subsurface materials can be developed. This exploration method is especially useful for estimating the depth of sand, gravel bedrock or water bearing strata, or for estimating the thickness of selected formations.

The second resistivity exploration technique is called electrical profiling. As in the case of sounding, numerous stations are selected. Resistivity measurements are then made, this time for the same depth, at each station.

These values once plotted, produce a numerical picture of the subsurface material at the chosen depth across a horizontal plane. Electrical profiling is most often used in searching for ore bodies, faults or fault zones, for evaluating sand and ground deposits, for delineating boundaries, and for finding dipping contacts of different earth materials.

\section{Field procedure}

Resistivity methods are employed for both lateral and vertical exploration.

- Lateral exploration (or horizontal profiling) - A series of measurements of resistivity are made with a constant electrode spacing, moving the whole of the electrode arrangements consecutively to a number of points. Thus the lateral variations of resistivity of the ground can be measured. The resistivities so detained are plotted on the control points along a profile.

This method of exploration is termed "constant depth traversing".

- Vertical exploration (or depth sounding) - A series of measurements of resistivity are made by increasing the electrode spacing in successive steps about a fixed point. This method of vertical exploration is known as 
the "expanding electrode method", "resistivity sounding" or "depth probing".

It is known as vertical electrical sounding (VES). The basis for making an electrical sounding, irrespective of the electrode array used is that the further away from the current source the measurement of the potential, or the potential difference of the electric field is made, the deeper the probing will be. It has been stated in many references on geophysical prospecting that the depth of probing depends on how far apart two current electrodes are placed. Furthermore, when sounding with a Wenner or Schlumberger array, when the distance between the current electrodes are increased, the distance between the current and potential electrodes, at the centre of the array is also increased. It is this latter increase that actually matters. In electrical sounding with the Wenner, Schlumberger arrays, the respective electrode spacing as $\mathrm{AB} / 2$ is increased at successive intervals and the value of the appropriate apparent resistivity $\mathrm{W}, \mathrm{s}$ is plotted as a function of the electrode spacing on logarithmic co-ordinate paper. The curve of $\vartheta=\mathrm{f}(\mathrm{a}) \mathrm{AB} / 2$ is called an electrical sounding curve.

Only vertical electrical sounding (VES) or depth sounding was carried out in the study area.

\section{Interpretation of curves}

The ability of a rock unit to conduct an electrical current depends primarily on three factors.

- The amount of open space between particles (Porosity).

- The degree of interconnection between those open space.
- The volume and conductivity of the water in the pores.

The presence of water and its chemical character are the principal controls on the flow of the electric current because most rock particles offer high resistance to electrical flow. Thus, resistivity decreases as porosity, hydraulic conductivity, water content and water salinity increase. Clay and Shale have low resistivities than do saturated sand and gravel.

There are two approaches in interpreting the resistivity data;

- Qualitative

\section{- Quantitative}

In qualitative interpretation the potential zone is found out by studying the nature of the field curve. In quantitative interpretation there are again two approaches

- Indirect method

- Direct method

In indirect method, the theoretically computed master curves are used to find out layer parameters by curve matching technique where as in direct method, computers are employed to find out the layer parameters.

\section{Discussions and conclusions}

Due to economic considerations and restrictions for the financial support, exploration geophysics has not played an important role in ground water investigations as much as it has in petroleum and mineral exploration. It is the primary concern of societies and voluntary organisations to develop the water resources especially in arid and semi-arid regions. Due to population increase and indus-

Table 1: Resistivities and thickness of different layers 
Figure 1(a): Electrical circuit for resistivity determination 
trialisation and also due to pollution of major resources, water has become more acute. The problem is basically technical, economic and political consideration for the management of adequate resources of fresh water.

Vertical electrical sounding have been carried out at many selected points in villages Bellairu, Padupanambur and Tokur in Mangalore-Karnataka, South India, using resistivity meter, employing Schlumberger electrode arrangements. During the field survey, the apparent resistivities obtained for different electrode spacing are recorded. These apparent resistivities are plotted against current electrode spacing as double log graph sheets having 62.5 modulus to get the field curves. The field curves are interpreted from curve matching technique.

The resistivities of the first layer varies from 100-400 ohm-m. Where are the resistivities of the second layer varies from 10-100 ohm-m. But the resistivity increases in the deeper zones and is sometimes above $1000 \mathrm{ohm}-\mathrm{m}$. Therefore, the second layer is interpreted as the saturated zone from which sufficient water may be tapped.

\section{References}

1 Dathu Rao, D., and Basavana Gowd, R.M., (1981) Soil and water testing manual, Soil Chemistry Division Government of Karnataka (KSDA).

2 Fleming, P.M., and Smiles, D.E., (1975) Infiltration of water into soil, in Proc, National symposium on $\mathrm{Hy}$ drology prediction in catchment hydrology, Australian academy of sciences, Canberra, November PP. 83-110.

3 Gajendragad M.R., Ranganna G., and Gurappa K.M., (1982) Adverse effect of improper irrigational practices and polluted ground water on farm production in coastal regions - A case study, Internal symposium, IAH, Prague Czechoslovakia.

4 Horton, R.E., (1940) The role of infiltration in the hydrological cycle, am geophy. Union trans., 14, pp 446-460.
5 Horton, R.E., (1940) Proc. of Amer. Soc. of soil science, 5 pp. 399.

6 Karanth, K.R., (1978) Studies of hydrological parameters of groundwater recharge in water balance computations in Andhra Pradesh, Hydrology review, a contribtion to IHP CSIR, New Delhi, 4(1-4) pp. 65.

7 Karanth K.R.(1988) Groundwater assessment development and management, Tata McGraw-Hill Publishing Company Ltd. pp.26.

8 Kuchibhatla K.R. (1988) Role of geophysics for groundwater resources, Groundwater New Oct-Nov.

9 Lokesh K.N., Naganna C., Srinivas G., (1983) Resistivity surveys for groundwater location in Bangalore University Campus Area, Jour. Assoc. Expl. Geophys., Vol. III, 4: pp35-39.

${ }^{10}$ Panchanathan P.V., Soman K., (1982) on the resistivity characteristics of selected literate profiles in parts of South Kerala, Jour. Assoc. Exp. Geophys. Vol. III, No. 2, pp. 7-11.

${ }^{11}$ Raju T.S. (1986) Infiltration process and techniques of measurement. Bhu-Jal News, Vol. No.3Quarterly Journal of Central Groundwater Board, pp. 8-11.

12 Ramachandra Rao, M.B., (1975) outlines of geophysical prospecting, A manual for geologists, Mysore Univeristy Pub.

${ }^{13}$ Rijkswatersaat, The Netherlands (1975) Standard graphys for resistivity prospecting, Pub. by European Assocn. of Exploration geophysicists.

${ }^{14}$ Rae, K.N., (1988) Resistivity Survey - Advantages and limitations - a review, groundwater news, Oct-Nov.

${ }^{15}$ Walton Williams C., (1970) Groundwater resources evaluation, McGraw Hill Book Co., New York. 